\title{
Gastric Diffuse Adenocarcinoma
}

National Cancer Institute

\section{Source}

National Cancer Institute. Gastric Diffuse Adenocarcinoma. NCI Thesaurus. Code C9159.

An adenocarcinoma arising from the stomach. Microscopically, it is characterized by the presence of a diffuse infiltrate, composed of individual adenocarcinoma cells or groups of adenocarcinoma cells in a fibrous or mucoid stroma. Many cells contain mucin droplets, producing a signet-ring configuration. 